\title{
Intrathoracic kidney: a rare finding in an infrequent syndrome
}

\section{KEYWORDS: Mayer-Rokitansky-Küster-Hauser síndrome - pitfalls = infrequent findings = bone scintigraphy}

We report 67 year old woman with a right colon cancer, which was recently diagnosed, who has undergone a whole-body bone scintigraphy. Despite no bone metastasis were found in the study, examination of bone scan revealed that physiological renal elimination of radiotracer was mimicking heart silhouette, which could be mistaken with other pathologies as a myocardial infarct (Panel A, arrow). Coronal and axial views of CT (Panel $\mathrm{B}$, arrows) helped to demonstrate that left kidney, part of the colon and the spleen were intrathoracic due to a major diaphragmatic hernia. The patient was suffering from a Mayer-Rokitansky-KüsterHauser syndrome, a disorder that occurs in females and mainly affects the reproductive system, which associated little inguinal hernia and a major diaphragmatic one (only less than $10-15 \%$ of this syndrome cases include herniations) (FIGURE 1).

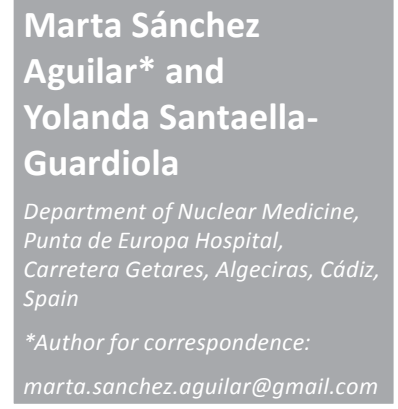

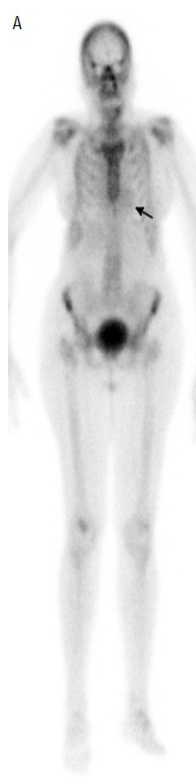

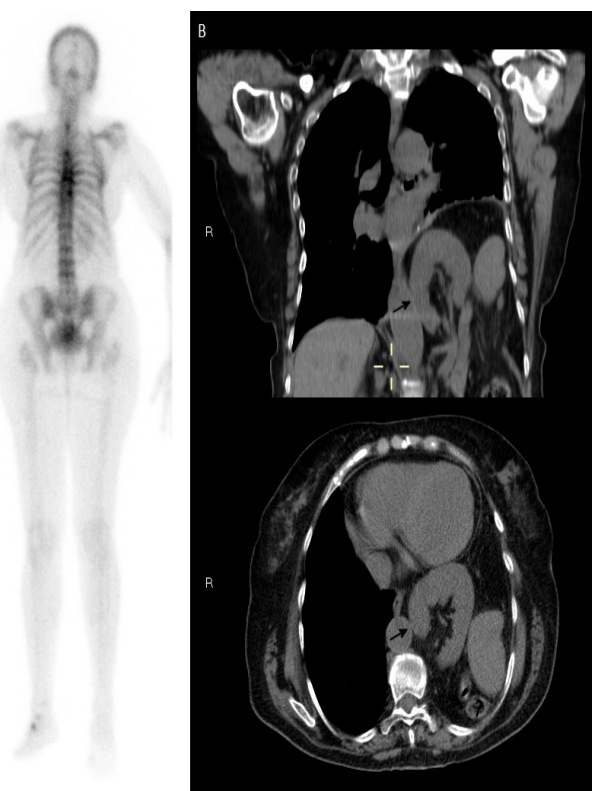

Figure 1. 